\title{
Evolution in soft tissue sarcoma
}

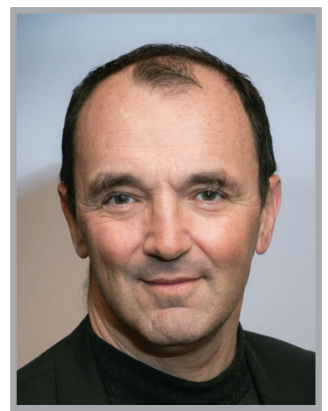

Jean-Yves Blay*

\author{
“...the most important determinant of outcome in \\ soft tissue sarcomas is the quality of initial \\ management."
}

First draft submitted: 11 November 2016; Accepted for publication: 14 November 2016; Published online: 5 December 2016

Although soft tissue sarcomas (STS) comprise $<2 \%$ of all cancers, they have been and continue to be valuable models for general oncology, guiding treatment paradigms for the entire oncological field. Approaches such as targeted therapy, adjuvant treatment and management of conservative surgery have all been piloted and led by the sarcoma community. Nevertheless, at the day-to-day level, managing STS remains a formidable challenge.

Sarcomas are a complex and highly heterogeneous set of diseases, with more than 80 known histological subtypes [1]. Marked differences in clinical presentation at various body sites in which tumors can develop further complicates the selection of treatment. In the main, STSs are aggressive neoplasms characterized by substantial rates of local relapse (20-30\%) and distant metastases (30-50\%). Only minimal improvements in 5-year survival (55-65\%) have been achieved over the past 5 years. As sarcomas are relatively rare (annual incidence 4-5/100,000 inhabitants in Europe), exposure in general oncological practice tends to be limited. When deciding a therapeutic strategy, numerous factors related to tumor characteristics, clinical characteristics and treatment goals must be taken into account during the course of shared decision-making. A multidisciplinary approach is considered essential toward providing best care for the patient.

Over the past 15 years, the classification of STS and its treatment has changed profoundly. Histological classifications are now supplemented by molecular subclassifications, which strongly influence prognosis and guide treatment decisions. More than ever, sarcomas are regarded as a complex and fragmented collection of uncommon entities, altogether rare and often extremely rare. Not surprisingly, this epidemiological refinement has had a major influence on treatment. Treatment is no longer regarded as a 'one-size-fitsall' approach. Patients with localized and advanced stages of STS are being treated according to newer strategies developed during this time frame. Moreover, the sharp increase in the number of clinical trials focusing on a single histological subtype has resulted in much more data to interpret and many more clinical guideline

*Centre Léon-Bérard, University Claude Bernard Lyon I, Lyon, France; jean-yves.blay@lyon.unicancer.fr

\section{KEYWORDS}

- histology-driven treatment

- reference centers $\bullet$ soft tissue sarcoma
Future
Medicine 


\section{References}

1 Blay JY, Sleijfer S, Schöffski P et al. International expert opinion on patient- recommendations to assimilate during the process of clinical-decision making.

Unequivocally, the most important determinant of outcome in STS is the quality of initial management [2]. Given that management of these rare tumors requires specific expertise, initial treatment in a reference center is considered to be crucial for best patient care. With this in mind, a group of renowned sarcoma oncologists from centers of excellence across Europe and the USA were brought together in March 2016 for a symposium entitled Soft Tissue Sarcoma: Evidence and Experience. Throughout the course of the meeting, the international panel of experts reviewed past, current and future (ongoing) studies of sarcoma management and exchanged perspectives on a diverse range of topical issues. It was my pleasure to chair this meeting and to now have the opportunity to share the proceedings with a global audience.

\section{Financial \& competing interests disclosure}

$J-Y$ Blay has received grants and research support from Bayer, Bristol-Myers Squibb, GlaxoSmithKline, Lilly, Merck Sharp \& Dohme, Novartis, PharmaMar and Roche. The author has no other relevant affiliations or financial involvement with any organization or entity with a financial interest in or financial conflict with the subject matter or materials discussed in the manuscript apart from those disclosed.

Editorial assistance was provided by Content Ed Net (Madrid, Spain) with funding from PharmaMar, Madrid, Spain. tailored management of soft tissue sarcomas. Eur. J. Cancer 50(4), 679-689 (2014).

2
ESMO/European Sarcoma Network Working Group. Soft tissue and visceral sarcomas:
ESMO clinical practice guidelines for diagnosis, treatment and follow-up. Ann. Oncol. 23(Suppl. 7), vii92-vii99 (2012). 